\title{
The efficacy of different sources of mesenchymal stem cells for the treatment of knee osteoarthritis
}

\author{
Maryam Shariatzadeh $^{1} \cdot$ Jianing Song ${ }^{2} \cdot$ Samantha Louise Wilson $^{3}$ \\ Received: 30 April 2018 / Accepted: 14 June 2019 / Published online: 15 July 2019 \\ (C) The Author(s) 2019, corrected publication 2019
}

\begin{abstract}
Osteoarthritis (OA) is a common cause of chronic pain and disability. Regenerative therapies using mesenchymal stem cells (MSCs) provide an option for OA treatment as it could potentially regenerate the damaged cartilage. Bone marrow, adipose tissue and synovium are common MSC sources. The aim is to compare the therapeutic effect of MSCs from bone marrow, adipose tissue and synovium; combining its differentiation potential and accessibility, to decide the optimal source of MSCs for the treatment of knee OA. A comparison of preclinical and clinical studies using MSCs has been made with regard to treatment outcomes, isolation procedure and differentiation potential. All types of MSCs are effective at improving the clinical and structural condition of OA patients, but the longevity of the treatment, i.e. an effect that is maintained for at least 2 years, cannot be guaranteed. This review highlighted great variations in selection criteria and culture expansion conditions of MSCs between the literature and clinical trials. It also emphasised a substantial diversity and lack of consistency in the assessment mythology of clinical outcome after completion of MSC therapies procedures. A more cohesive methodology is required to evaluate the outcome of MSC treatments using quantitative and standardised frameworks in order to be able to directly compare results. Larger population of patients are recommended to assess the quality of MSC when designing studies and clinical trials to reaffirm the efficacy of MSC treatment prior to and within the clinical trials and follow up studies.
\end{abstract}

Keywords Mesenchymal stem cells $\cdot$ Clinical outcome $\cdot$ Osteoarthritis $\cdot$ MSC therapies $\cdot$ Clinical trials

\section{Introduction}

Osteoarthritis (OA) is a degenerative and inflammatory joint disease (Fig. 1). The limited capacity of healing in articular cartilage results in cartilage destruction, osteophyte development and inflammation. The prevalence of knee OA has doubled since the mid-twentieth century, becoming one of the

The original version of this article was revised: There is an error in the original publication of this paper. The author names were incorrectly presented.

Samantha Louise Wilson

s.wilson2@lboro.ac.uk

1 Centre for Biological Engineering, Wolfson School of Mechanical, Electrical and Manufacturing Engineering, Loughborough University, Epinal Way, Loughborough LE11 3TU, UK

2 National Centre for Sport and Exercise Medicine, School of Sport, Exercise and Health Sciences, Loughborough Univeristy, Epinal Way, Loughborough LE11 3TU, UK

3 Centre for Biological Engineering, Wolfson School of Mechanical, Electrical and Manufacturing Engineering, Loughborough Univeristy, Epinal Way, Loughborough LE11 3TU, UK leading causes of chronic pain and lower-limb disability among elderly people in developed countries (Wallace et al. 2017).

Traditional pharmacological treatments, non-pharmacological treatments and surgical procedures can only offer symptomatic benefits, whereas the damaged cartilages currently cannot be effectively repaired. With the advance in regenerative medicine, mesenchymal stem cells (MSCs) have emerged as an alternative cellular therapy for the treatment of knee OA.

MSCs are a type of multipotent stromal cell (Fig. 2) which have the potential to differentiate into osteocytes and chondrocytes and are commonly used in regenerative therapies to treat cartilage defects. MSCs can be isolated and derived from a variety of autologous and allogenic locations such as bone marrow (BM MSC), adipose tissue (ADMSC), umbilical cord blood and dental pulp. However, evidence of the optimal source of MSCs remains unclear. A serious gap in knowledge remains whether the currently used cellular treatments are beneficial long-term or if one cell therapy offers significant clinical benefit with regard to reduced pain and improved quality of life (QoL).

\section{Comparison of cell courses}

Autologous bone marrow concentrate (BMAC) is a prevalent source of MSCs for the treatment of OA; this is due to the 
Fig. 1 A comparison of a healthy knee (left) and a demonstrating OA pathology (right); reproduced from (O’Connell et al. 2019)

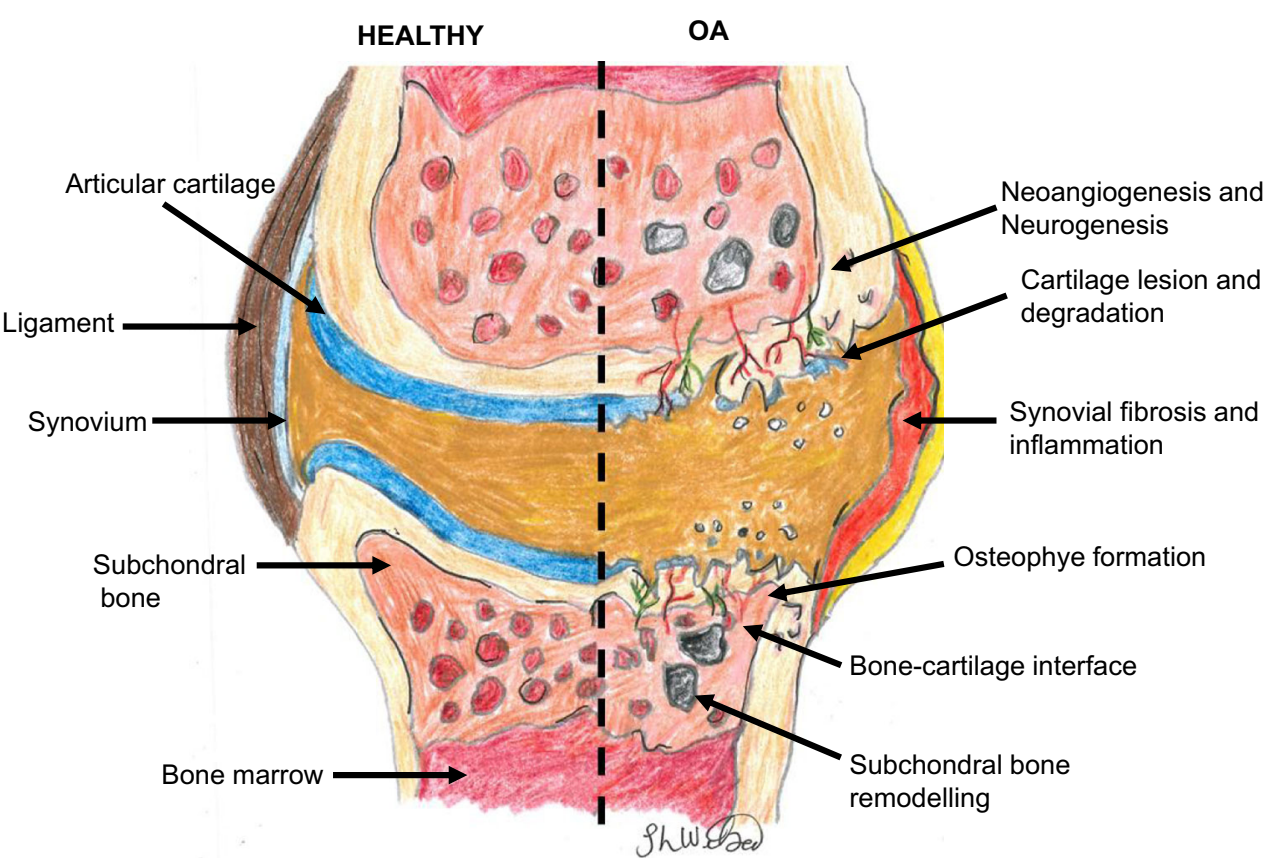

compared with other MSC sources and delivery procedures. Adipose tissue provides a rich source of MSCs in comparison to bone marrow, and as such is frequently used in a variety of

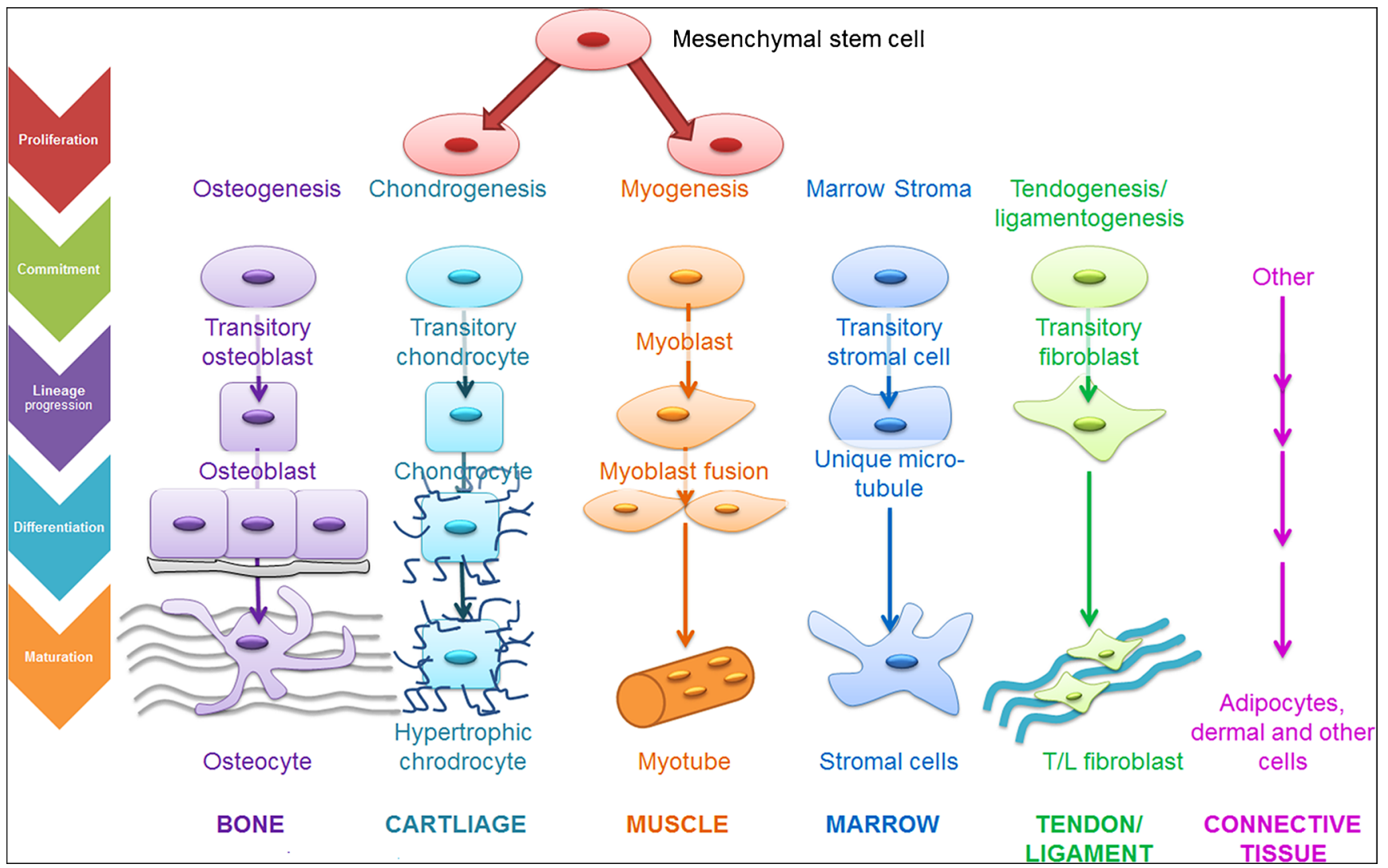

Fig. 2 The differentiation lineages of mesenchymal stem cells (MSCs) 
clinical and regenerative medicine research studies. The cellular components can be extracted as a cell pellet through washing and centrifugation steps which may also be referred to in literature as a stromal vascular fraction (SVF).

When deciding the optimal source of MSCs, information such as cell isolation procedure, harvest volume and differentiation potential should be considered. BMMSCs can be obtained from bone marrow, although the quantities are relatively low, with the number of MSCs often declining with increasing donor age (Wolfstadt et al. 2015); thus making it difficult to obtain sufficient cell numbers, especially among elderly donors. In contrast, 10 to 30 times more SMSCs can be derived from the same number of donors (Nimura et al. 2008; Sekiya et al. 2015) with yields of ADMSCs in the region of 500-fold more in comparison to BMMSCs (Hass et al. 2011). Furthermore, adipose tissue can be easily obtained by lipectomy and liposuction procedures, which are more wellestablished and less invasive in comparison to bone marrow aspiration (Puissant et al. 2005).

BMMSCs are more prone to chondrogenic differentiation in comparison to ADMSCs both in vitro and vivo (Danišovi et al. 2007; Koga et al. 2008b). However, Kim and Im (2009) have suggested that the addition of paracrine or cytokines factors increases chondrogenic potential in ADMSCs to levels similar to BMMSCs (Kim and Im 2009). Comparatively, SMSC studies have indicated that they possess higher chondrogenic potential in comparison to BMMSCs and ADMSCs (Sakaguchi et al. 2005; Futami et al. 2012). An interesting study by Shirasawa et al. 2006 demonstrated that when growth factors such as bone morphogenic factor 2 (BMP2), transforming growth factor beta (TGF- $\beta$ ) and dexamethasone are added to cultures, SMSCs produce more cartilaginous tissues compared with BMMSCs isolated from the same donors (Shirasawa et al. 2006). This suggests that SMMSCs may be more advantageous regarding chondrogenic differentiation potential.

Although the use of stem cell preparations for knee $\mathrm{OA}$ is becoming increasingly prevalent, well-designed studies with conclusive proof of comparative effectiveness and identification of the optimal cell source, delivery mechanism and "dose" have not been performed. Autologous BMMSCs and ADMSCs are two of the most commonly used cell sources in clinical trials (Wyles et al. 2015) (Table 3). However, researchers have increasing interest in synovial mesenchymal stem cells (SMSCs), which have been reported to have chondrogenic potential both in vivo and in vitro (Sakaguchi et al. 2005; Koga et al. 2008a). The beneficial effect of promoting cartilage regeneration has been reported in leporine models (Koga et al. 2008b) and porcine studies (Nakamura et al. 2012), resulting in SMSCs now being considered to be an alternative for MSCs treatment of knee OA.

This review focuses in comparing clinical studies and different types of MSC-based treatments to identify a preferential source of stem cells for the treatment of knee OA Completed and active clinical trials (Table 3) and approved/authorised market products (Table 4) have all been evaluated.

\section{Comparison of European pre-clinical studies}

Many preclinical studies have investigated the use of MSCs from different sources for the treatment if knee OA (Table 1). In general, BM-derived MSC's are the most prevalent source the in EU, followed by adipose-derived MSCs. The literature search revealed that only one study reported the use of SMMSC's for the treatment of knee OA.

Within the EU, currently Spain is the most prevalent with regard to published literature regarding MSC therapies for the treatment of OA. Of the studies reviewed, five studies performed intra-articular injection of both allogenic and autologous BM-MSCs and favourably presented the benefit of MSC therapies in improving both knee movement and pain management (Vega et al. 2015; Soler et al. 2016).

The number of MSCs utilised in published literature varies widely from $2 \times 10^{6}$ to $5 \times 10^{7}$ cells per patient (Soler et al. 2016; de Windt et al. 2017, Orozco et al. 2013; Pers et al. 2016). However, it is not clear if the dosage represents the total number of MSCs for each injection procedure or is referring to the number of injected cells per $\mathrm{kg}$ body weight. Furthermore, not all studies provide specific details regarding cell passage number, although it is apparent that MSCs with lower passage number (passage $2 / 3$ ) are more commonly used.

To determine the cell phenotype, a variety of surface markers and transcription factors varying dependent upon the different types and sources MSCs used can be used. However, regardless of the variation in the source of isolated MSCs, there are a number of surface markers that are commonplace; these include CD90, CD45 and CD34 which are used to characterise culture-expanded MSCs prior to use (Akgun et al. 2015; Vega et al. 2015; Pers et al. 2016; Soler et al. 2016; de Windt et al. 2017).

Of the studies examined, it became apparent that a range of medium and growth factors are utilised for in vitro and ex vivo expansion of stem cells including; DMEM, $\alpha$ MEM, (Orozco et al. 2013, (Vega et al. 2015) whilst, Russo et al. (2017) and Hudetz et al. (2017) reported the use of Lipogems ${ }^{\circledR}$ processing kit for processing MSCs which contains no medium (Hudetz et al. 2017; Russo et al. 2017).

The results of these European studies highlighted the variation in the number of patients that have currently undertaken MSCs therapy, which was reported between 7 and 56 patients per study. Regardless of the differences in MSC types, sources and/or the culture expansion conditions, most studies performed either a single or multiple intra-articular injection(s) to deliver the MSCs into the cartilage defect. A small number 


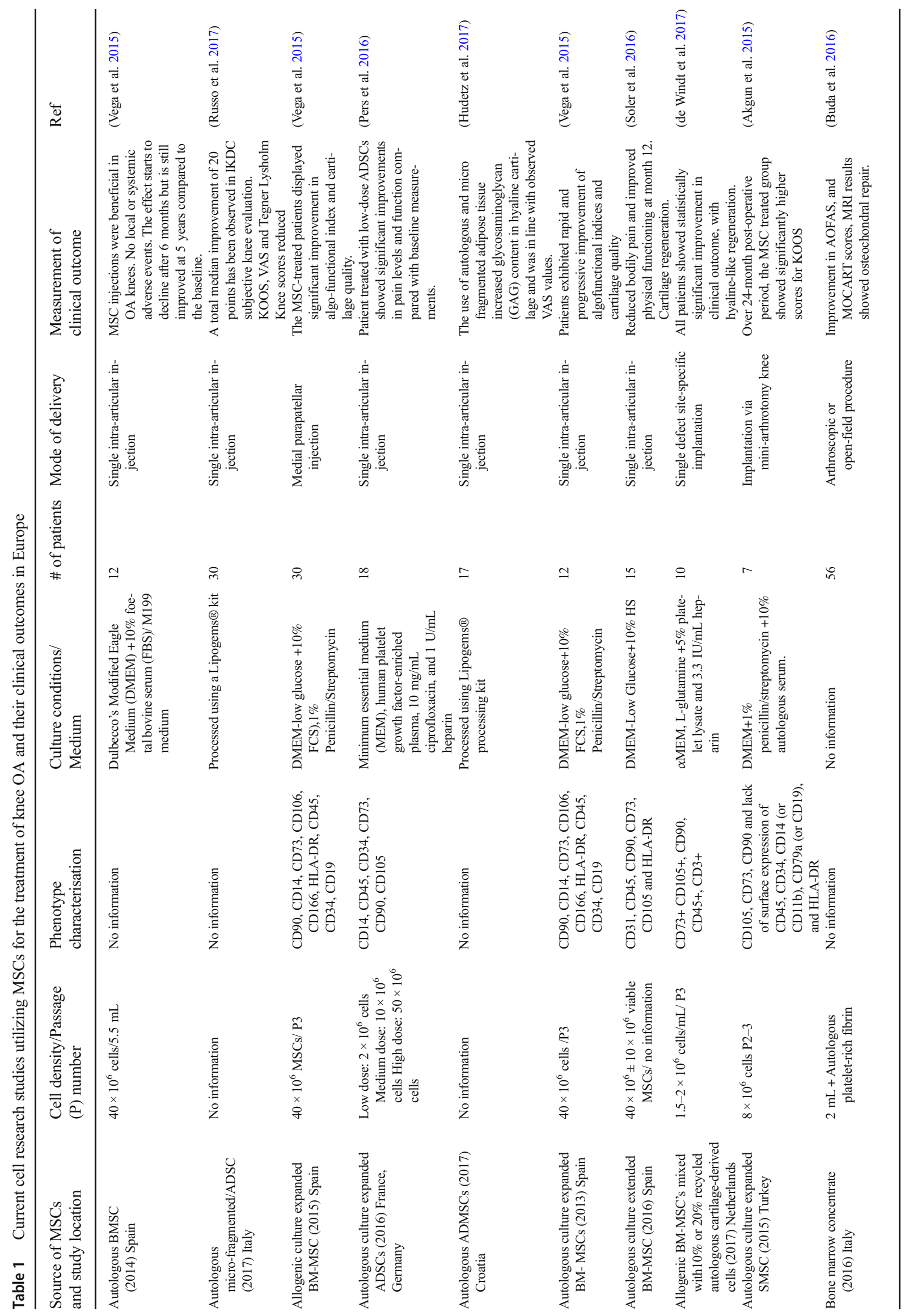


of studies delivered the MSCs via mini-arthrotomy or single defect site-specific knee implantation (Akgun et al. 2015; Buda et al. 2016)

The clinical outcome and effectiveness of MSC therapies are predominantly measured by qualitative test and questionnaires (Table 2) including the use of; the Visual Analogue Scale (VAS), Knee injury and Osteoarthritis Outcome Scores (KOOS), The Western Ontario and McMaster Universities Osteoarthritis Index (WOMAC) and International Knee Documentation Committee Questionnaire (IKDC). Although two studies performed GAG formation GAG in hyaline cartilage (Hudetz et al. 2017) and magnetic resonance imaging (MRI) analysis (Buda et al. 2016) to determine regeneration and osteochondral repair. The reliance on qualitative means that data collection is difficult to achieve using blinding strategies. Lack of blinding may lead to false-positive results reported by patients and researchers and an overestimation of the efficacy of the treatments under investigation. Moreover, the lack of control groups or comparative randomised trials and the tendency to compare results with baseline values may also lead to an over-estimation of the success of the treatment strategies.

It is difficult to directly compare the results of pre-clinical studies since the inclusion criteria lack consistency between studies; for example, patients often have existing preoperative conditions and have previously undergone surgical procedures which may significantly influence the clinical outcomes with varied efficacy of interactions. Furthermore, there is a lack of consistency in the methodologies employed, for example, the cell culture conditions, mode of delivery and the outcome measurements are variable and often reliant upon qualitative measures. This makes the efficacy of different sources difficult to compare. Furthermore, the predominant outcome measurements focus on cartilage regeneration, whilst overlooking the effect of MSCs on the surrounding milieu, such as paracrine effects, which although not as important as cartilage regeneration for treatment of knee OA, however, may still contribute to healing by inducing the signalling changes in nearby tissues.

\section{Comparison of completed phase I/II/III clinical trials using MSC therapies for the treatment of knee $O A$}

To date, there have been 22 completed clinical investigating the use of MSCs as a therapy for the treatment of knee OA at phase I, II and III between 2012 and 2018. Table 3 provides a comparison of these studies with criteria including cell source, dosage, expansion culture conditions, clinical outcome measures and information regarding the quality of utilised stem cells such as phenotype and passage number. Autologous and allogenic BM-MSCs are predominantly utilised, with nine studies reporting the use of either ex vivo or in vitro expanded culture of MSCs. Dependent upon the source of MSCs, the number of cells utilised in each clinical trial varied between $2.5 \times 10^{6}$ and $1 \times 10^{8}$ cells $/ \mathrm{kg}$ body weight, or in total. It was apparent that information regarding the cell passage number, phenotypes and expansion conditions were often absent on the clinical trials webpage (NIH US National Library of Medicine 2019). The mode of delivery was largely reported as intraarticular injection; however, a clinical trial carried out in Jordan reported the use of multiple intra-articular injections (Al-Najar et al. 2017).

For the majority of published trial studies, a follow up period of 12 months is commonplace following treatment with MSCs; however, the CARTISTEM $®$ clinical trial in Korea reported a follow up period of up to 60 months (Lim et al. 2017). Among the 22 clinical trials, only two countries, Korea and Iran, have to date, completed their phase III trials in 2017 and 2013 respectively, in which, allogenic hUCB-MSCs, under the commercial name "CARTISTEM", and autologous BM-MSC's were used as sources of stem cells for the treatment of OA (Park et al. 2017). However, there was no information available in the published Iranian clinical trial regarding the cell dosage and condition of culture expansion. In most clinical trials, the effectiveness of the MSC treatment are measured by qualitative clinical tests and questionnaires including; VAS, WOMAC, IKDC and KOOS; the studies have no or limited quantitative data available to support the effectiveness of stem cells treatments for cartilage regeneration. In addition, only seven studies performed MRI tests to assess the cartilage status prior and after receiving stem cell therapies.

Currently, the effect of MSC therapies cannot be guaranteed long-term (>60 months), since further significant improvement usually ceases during follow-up studies. Jo et al. (2017) pointed out that the effect of MSC-therapy does not last for long term. Although results are improved compared with baseline measurements, the outcomes still eventually plateau or start to decline within 2 years following intervention. Thus, combined treatment strategies combining other injectable agents, such as platelet-rich plasma (PRP) (O'Connell et al. 2019), should be investigated to determine their effect on enhancing engraftment efficiency (Atashi et al. 2015). Furthermore, there is a requirement for improved management of OA following treatments; this could include postintervention rehabilitation to optimise the therapeutic effect and guarantee a long-lasting efficacy (Fahy et al. 2017).

\section{Market authorised MSC products}

Despite the completion of the clinical and preclinical studies investigating the efficacy of MSC therapies for OA, to date, only five products have reached the market (Table 4). Remarkably, the dosage of these stem cell products is much 
Table 2 A summary of the rating scales and scores commonly used to evaluate the success of therapies of the knee

\author{
Name of rating scale \\ Western Ontario and McMaster Universities \\ Osteoarthritis Index (WOMAC)
Magnetic resonance observation of cartilage repair tissue (MOCART) \\ The American Orthopaedic Foot and Ankle \\ Society Score (AOFAS)
}

Lequesne indexes Knee Injury and Osteoarthritis Outcome
Score (KOOS)

Visual Analogue Scale (VAS)

International Knee Documentation Committee (IKDC)

Lysholm knee scores

Tegner activity level scale

36-Item Short Form Survey (SF-36)

Kellgren-Lawrence grade

Whole-Organ Magnetic Resonance Imaging Score (WORMS)
Brief description

A widely used self-evaluated questionnaire of knee OA. There are 3 subscales to assess pain (5 items, $0-20$ scores), stiffness ( 2 items, $0-8$ scores) and physical function (17 items, $0-68$ scores) separately. Higher scores suggest increased pain, stiffness and functional limitation.

A 9-part and 29-item system, that gives a final cartilage repair tissue score between 0 and 100 points; 0 points represents a poor outcome; 100 points represents a positive outcome

One of the most widely used measures for foot and ankle conditions comprised of subjective and objective questions; each section is designed to be used independent of the others. However, each measure is comprised of nine questions and cover three categories: pain ( 40 points), function ( 50 points) and alignment (10 points). These are all scored together for a total of 100 points.

An index of severity for knee OA, which can also be used to assess the effectiveness of therapeutic interventions. 3 sections include pain or discomfort, maximum distance walked, and activities of daily living. A score of 0 indicates no limitation; whilst a score $<8$ is regarded as a severe limitation. Detailed scoring systems and modifications had been published (Lequesne et al. 1987; Lequesne 1991, 1997).

A self-administered multiple-choice questionnaire comprised of categories: Symptoms; Stiffness; Pain; Function (daily living); Function (Sports and Recreational activities); Quality of Life

A self-administrated evaluation to measure the amount of the pain that patients feels across a continuum number presenting from none to an extreme amount of pain (D. Gould et al. 2001).

A group of knee surgeons from Europe and America founded in 1987: A common terminology and an evaluation form were created. This form is the standard form for use in all publications on results of treatment of knee ligament injuries.

A self-evaluated questionnaire consisted by 8 sections, $<65$ scores are defined as 'Poor', 65-83 scores are 'Fair', 84-90 scores are 'good', and >90 scores are 'Excellent'. Detailed score and grading were previously described (Tegner and Lysholm 1985; Mitsou et al. 1990).

A complement for Lysholm scale focussed on activities of daily living, recreation and competitive sports. The scores vary from 0 to 10 . Scores $>6$ can only be achieved by recreational or competitive sports participants.

A patient-reported survey has 36 items which concerning on quality-of-life. SF-36 consists of 8 scales, with 100 scores in each scale, and higher scores indicate the less disability. Detailed information had been previously published (Ware and Sherbourne 1992; McHorney et al. 1993; McHorney et al. 1994)

The grade classifies the severity of knee OA into 5 grades, 0 refers to no radiographic features, and grade 4 is the most severe with large osteophytes, marked joint space narrowing, severe sclerosis and definite bony deformity. Further information refers to the study of Kellgren and Lawrence (1957)

An MRI scoring method that incorporates articular cartilage integrity, subarticular bone marrow abnormality, subarticular cysts, subarticular bone attrition, marginal osteophytes, medial and lateral meniscal integrity, anterior and posterior cruciate ligament integrity, medial and lateral collateral ligament integrity, synovitis/effusion, intraarticular loose bodies, and periarticular cysts/bursitis. lower than the cell numbers reported in either clinical trials or research studies.

TRINITY EVOLUTION®, an allogenic graft-containing adult MSCs, osteoprogenitor cells (OPCs) and demineralised cortical components has been approved by the Musculoskeletal Transplant Foundation (MTF) committee (Musculoskeletal Transplant Foundation 2013) in the USA for administration in the treatment of OA-related cartilage damage and for ankle and foot surgical applications. However, there is no information available regarding the cell dosage and expansion culture conditions for MSCs and OPCs cell components (Rush 2010). Nevertheless, the published phase III large animal clinical studies demonstrated that an increase in MSC dosage resulted in increased fusion and healing rates (Wheeler et al. 2014). Other studies have confirmed that there is a minimum cell dose required for effective 


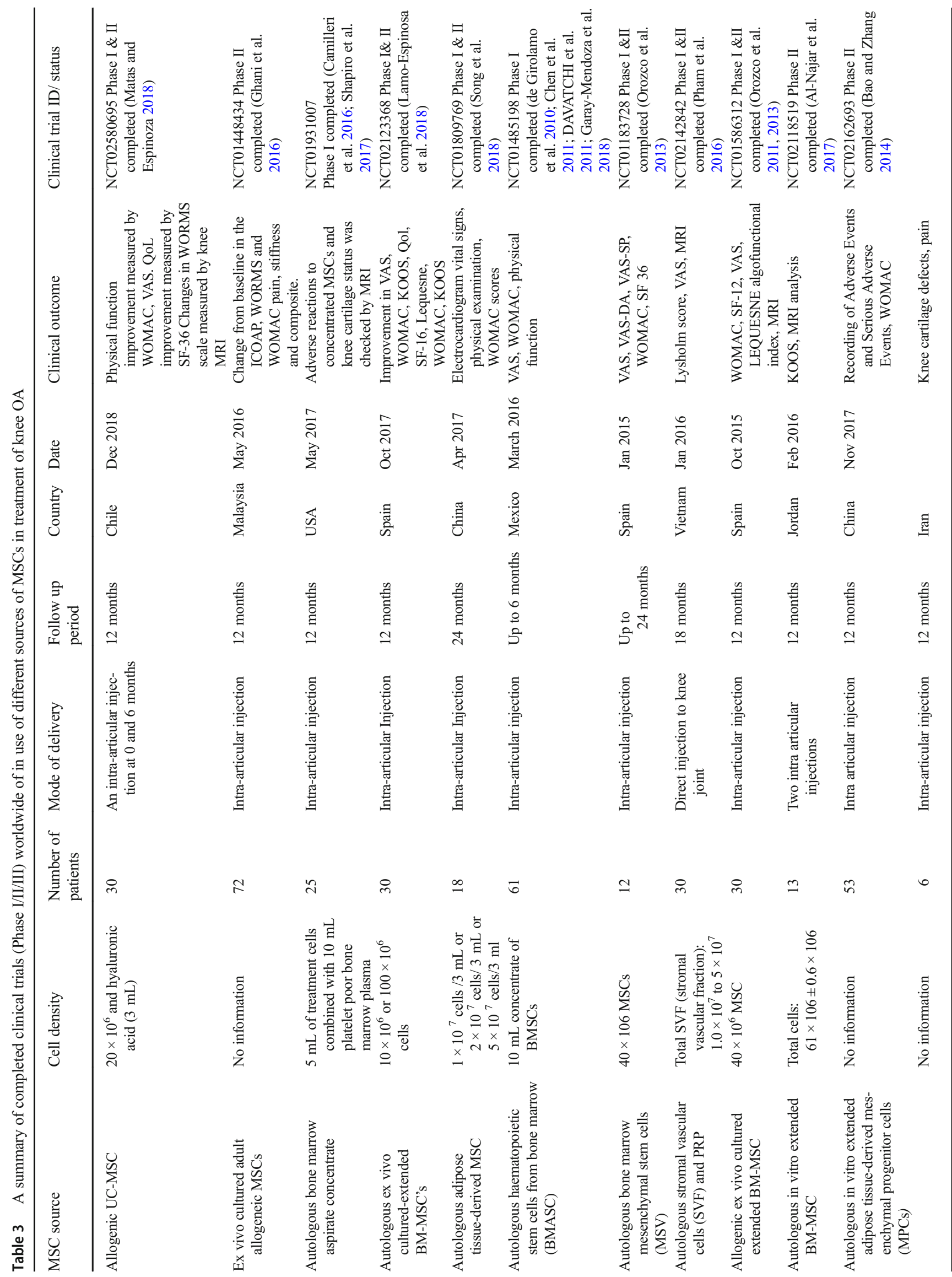




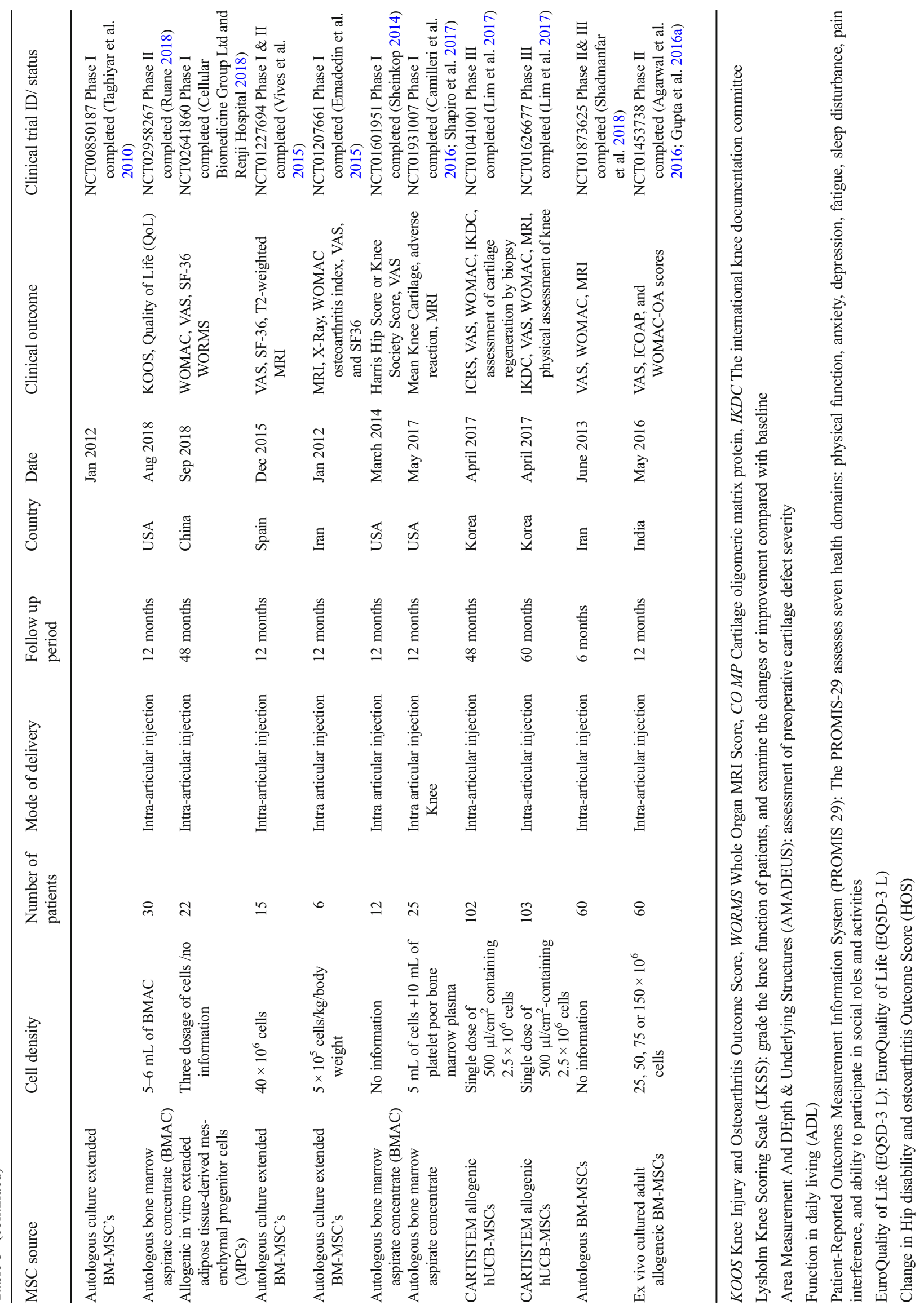


Table 4 Market authorised MSC/cell-based products for treatment of OA

\begin{tabular}{|c|c|c|c|c|}
\hline Product name & Cell dosage & Regulatory approval & Country & Administration technique \\
\hline $\begin{array}{l}\text { TRINITY EVOLUTION® } \\
\text { allogenic graft containing adult } \\
\text { MSCs and osteoprogenitor cells } \\
\text { (OPCs) (Rush 2010; Orthofix(R) } \\
\text { 2019) }\end{array}$ & No information & $\begin{array}{l}\text { Musculoskeletal transplant } \\
\text { foundation (MTF) commit- } \\
\text { tee approved }\end{array}$ & USA & $\begin{array}{l}\text { Ankle and foot/surgical } \\
\text { applications }\end{array}$ \\
\hline $\begin{array}{l}\text { Tonogenchoncel-L (Invossa) } \\
\text { Allogeneic human chondrocytes } \\
\text { at a ratio of } 3: 1 \text { of unmodified } \\
\text { chondrocytes to genetically mod- } \\
\text { ified chondrocytes expressing } \\
\text { TGF- } \beta 1 \text { cells (Lee } 2018 \text { ) }\end{array}$ & $3 \times 10^{7}$ cells $/ 2 \mathrm{~mL}$ & & South Korea & $\begin{array}{l}\text { Intra-articular injection to } \\
\text { the knee }\end{array}$ \\
\hline $\begin{array}{l}\text { CARTISTEM® Allogeneic } \\
\text { umbilical cord blood-derived } \\
\text { MSC (Park et al. 2017; Lee 2018) }\end{array}$ & $\begin{array}{l}2.5 \times 10^{6} \\
\quad \text { cells } / 500 \mu \mathrm{L} / \mathrm{cm}^{2}\end{array}$ & $\begin{array}{l}\text { Advanced therapy medicinal } \\
\text { product (ATMP) approved } \\
\text { in EU }\end{array}$ & $\begin{array}{l}\text { South Korea, Medipost, } \\
\text { UK }\end{array}$ & $\begin{array}{l}\text { Intra-articular injection to } \\
\text { the knee }\end{array}$ \\
\hline $\begin{array}{l}\text { Stem peucel@ Allogenic ex vivo } \\
\text { cultured, pooled, human } \\
\text { BM-MSC (Gupta et al. 2016a; } \\
\text { STEMPEUTICS RESEARCH } \\
\text { PVT LTD 2019) }\end{array}$ & $2 \times 10^{8} / 15 \mathrm{~mL}$ & $\begin{array}{l}\text { ATMP approved in EU- limit- } \\
\text { ed market sale approved by } \\
\text { Indian Food and Drugs } \\
\text { Administration (FDA) }\end{array}$ & India & $\begin{array}{l}\text { No obvious embodiment } \\
\text { for treatment of OA }\end{array}$ \\
\hline $\begin{array}{l}\text { Joint Stem Autologous adipose } \\
\text { derived mesenchymal stem cells } \\
\text { (Jo et al. 2014) }\end{array}$ & $\begin{array}{l}10 \times 10^{7} \text { cells per } \\
\text { injection }\end{array}$ & $\begin{array}{l}\text { Approved clinical trial phase I } \\
\text { completed in USA }\end{array}$ & $\begin{array}{l}\text { Korea (Biostar Stem Cell } \\
\text { Technology Research } \\
\text { Institute) }\end{array}$ & $\begin{array}{l}\text { Single or repeated } \\
\text { intra-articular injection } \\
\text { to the knee }\end{array}$ \\
\hline
\end{tabular}

regenerative outcomes, although more MSCs do not necessarily result in increased rates of healing. Although the reason for this is unclear, some studies have highlighted that a minimum number of MSCs are essential to enhance the healing cascade; whereas high doses of MSCs may lead to overpopulation and stem cell competition for nutrients within the graft area (Liebergall et al. 2013)

CARTISTEM $®$, the world's first allogeneic cord bloodderived mesenchymal stem cell drug was received its market approval by the Food and Drugs Administration (FDA) and was released in South Korea in 2012. The MSC-based product contains $2.5 \times 10^{6}$ cells $/ 500 \mu \mathrm{L} / \mathrm{cm}^{2}$ area of the knee cartilage defect and was recently approved by the European Medicines Agency (EMA) as an advanced therapy medicinal product (ATMP) for use as a single dose therapeutic agent for treatment of OA. The extended follow-up clinical studies for CARTISTEM ${ }^{\circledR}$ were completed in 2016, and its manufacturing production exceeded 5,000 vials in 2017 (Park et al. 2017). This product was developed by Medipost Co. Ltd. (MEDIPOST Co. 2019) as an off-shelf stem cell drug and recently completed Phase III clinical trials in the USA. The long-term efficacy of CARTISTEM $®$ treatment is yet to be determined, thus this needs to be addressed through phase IV clinical trials (Sridharan et al. 2016).

Stempeucell®, an allogenic ex vivo cultured, pooled, human BM-MSC-based product launched in India. Although, it is ATMP approved and has been realised in the EU, the Indian FDA has currently only approved limited market sales in India due to uncompleted clinical trials. The cell dose contains $2 \times$
$10^{8}$ expanded BMMSCs that are cryopreserved and stored in $15 \mathrm{~mL}$ cryo-bags. The cells demonstrate a high expression level of MSC phenotype markers including CD73, CD105, CD90 and CD166 (Gupta et al. 2016b). Gupta el al. have demonstrated the safety of intra-articular administration of Stempeucel $\AA$; however, a $25 \times 10^{6}$ cell dose proved to be the most effective amongst the doses tested for pain reduction. Therefore, clinical studies with a larger patient population are required to validate the therapeutic efficacy of Stempeucel ${ }^{\circledR}$ for treatment of OA.

JointStem, an autologous stem cell-based product, contains $10 \times 10^{7}$ adipose-derived MSCs and was developed by Biostar Stem Cell Technology Research Institute of K Stem Cell (formerly R\&R Bio) in Korea (Biostar stem cell Research and Development 2017). Jointstem is delivered via injection into the glenoid cavity of degenerative arthritis patients and is expected to renew their cartilage, alleviate pain and improve joint functions. The JointStem was approved for regenerative medical treatment for degenerative arthritis from Japan Health and Welfare Ministry in 2015 (R-Japan Co. Ltd 2015). The drug's efficacy and safety for single and repeated admiration are being currently assessed in phase II clinical trial in USA (Jo et al. 2014).

\section{Conclusion}

The application of MSC therapies for the treatment of OA is evolving swiftly despite a current lack of concrete evidence to support its long-term efficacy. Regardless of differences in 
MSC sources, the literature and clinical trials have no cohesive information regarding the collection/isolation, culture conditions and characterisation criteria, quality, mode of action or administration of the stem cells. We have reported that defining the cell dosage and MSC characteristics are currently present a hurdle that must be overcome to identify the quality of MSCs as therapeutic agents, particularly when comparing the clinical outcomes and efficacy of preclinical, clinical and market authorised cell therapy treatments.

Currently, numerous qualitative often subjective, clinical measurements are applied to assess the efficacy and effectiveness of MSC treatments, which may not faithfully represent the accurate potency and efficiency of the therapy. Therefore, efficacy follow-up systems are required to monitor the dynamics of efficacy and to help in evaluating the requirement for reapplication of the MSC product. Moreover, the efficacy monitoring allows the generation of the information that will appropriately reflect the periods of required reapplication in clinical practice. Such systems include more sensitive (and less subjective) quantitative tests, acceptable surrogate methods and more comparative design that are essential in long-term follow-up assessment of clinical, safety and efficacy of MSCbased products. The results of number of European studies and clinical trials revealed that BM-MSCs are the predominant cell source; however, the optimal source of MSCs is still speculative when considering combining the cell preparation procedure, differentiation potential and durable effect of MSCs. Additionally, a more consistent methodology is vital to evaluate the outcome of regenerative treatment in a more standardised and comparable frame whilst, larger patient number reaffirm the efficacy of MSC treatment within clinical trials and follow-up studies. Despite the numerous clinical trials and research studies that have used MSC for the treatment of knee OA, only five MSC products have reached the market with only two products including; CARTISTEM $®$ and Stempeucell囚, receiving approval by ATMPs for clinical application in EU. The massive gaps between clinical trials, cell therapies regulatory bodies and the market show that completion of clinical trial and approval of an MSC product does not guarantee its clinical application due to the issues with reimbursement and the cost of final product.

\section{Compliance with ethical standards}

Conflict of interest The authors declare that they have no conflict of interest.

Open Access This article is distributed under the terms of the Creative Commons Attribution 4.0 International License (http:// creativecommons.org/licenses/by/4.0/), which permits unrestricted use, distribution, and reproduction in any medium, provided you give appropriate credit to the original author(s) and the source, provide a link to the Creative Commons license, and indicate if changes were made.

\section{References}

Agarwal, V. et al. (2016) Allogeneic mesenchymal stem cells in osteoarthritis - Full Text View - ClinicalTrials.gov. Available at: https:// clinicaltrials.gov/ct2/show/NCT01453738 (Accessed: 14 May 2019).

Akgun I et al (2015) Matrix-induced autologous mesenchymal stem cell implantation versus matrix-induced autologous chondrocyte implantation in the treatment of chondral defects of the knee: a 2year randomized study. Arch Orthop Trauma Surg 135(2):251263. https://doi.org/10.1007/s00402-014-2136-z

Al-Najar M et al (2017) Intra-articular injection of expanded autologous bone marrow mesenchymal cells in moderate and severe knee osteoarthritis is safe: a phase I/II study. J Orthop Surg Res 12(1):190. https://doi.org/10.1186/s13018-017-0689-6

Atashi F et al (2015) Autologous platelet-rich plasma: a biological supplement to enhance adipose-derived mesenchymal stem cell expansion. Tissue Eng Part C Methods 21(3):253-262. https://doi.org/10. 1089/ten.tec.2014.0206

Bao C, Zhang Z (2014) Clinical trial of autologous adipose tissue-derived mesenchymal progenitor cells (MPCs) therapy for knee osteoarthritis - Full Text View - ClinicalTrials.gov. Available at: https:// clinicaltrials.gov/ct2/show/NCT02162693 (Accessed: 14 May 2019)

Biostar stem cell Research and Development (2017) Stem Cell | Biostar Stemcell Research Institute. Available at: http://www.stemcellbio. com/tag/stem-cell/ (Accessed: 14 May 2019)

Buda R et al (2016) “One-step" bone marrow-derived cells transplantation and joint debridement for osteochondral lesions of the talus in ankle osteoarthritis: clinical and radiological outcomes at 36 months. Arch Orthop Trauma Surg 136(1):107-116. https://doi.org/10.1007/ s00402-015-2344-1

Camilleri ET et al (2016) Identification and validation of multiple cell surface markers of clinical-grade adipose-derived mesenchymal stromal cells as novel release criteria for good manufacturing practice-compliant production. Stem Cell Res Ther 7(1):107. https://doi.org/10.1186/s13287-016-0370-8.

Cellular Biomedicine Group Ltd and Renji Hospital (2018) Clinical trial of allogenic adipose tissue-derived mesenchymal progenitor cells therapy for knee osteoarthritis - Full Text View ClinicalTrials.gov. Available at: https://clinicaltrials.gov/ct2/show/ NCT02641860 (Accessed: 14 May 2019)

Chen F-M et al (2011) Homing of endogenous stem/progenitor cells for in situ tissue regeneration: promises, strategies, and translational perspectives. Biomaterials 32(12):3189-3209. https://doi.org/10. 1016/j.biomaterials.2010.12.032

Danišovi L' et al (2007) Chondrogenic differentiation of human bone marrow and adipose tissue-derived mesenchymal stem cells. J Appl Biomed 5(Buckwalter 1998):139-150

DAVATCHI F et al (2011) Mesenchymal stem cell therapy for knee osteoarthritis. Preliminary report of four patients. Int J Rheum Dis 14(2):211-215. https://doi.org/10.1111/j.1756-185X.2011.01599.x

Emadedin M et al (2015) Long-term follow-up of intra-articular injection of autologous mesenchymal stem cells in patients with knee, ankle, or hip osteoarthritis. Arch Iran Med 18(6):336-344

Fahy N, Alini M, Stoddart MJ (2017) Mechanical stimulation of mesenchymal stem cells: implications for cartilage tissue engineering. $\mathrm{J}$ Orthop Res. https://doi.org/10.1002/jor.23670

Futami I, Ishijima M, Kaneko H, Tsuji K, Ichikawa-Tomikawa N, Sadatsuki R, Muneta T, Arikawa-Hirasawa E, Sekiya I and Kaneko K (2012) Isolation and characterization of multipotential mesenchymal cells from the mouse synovium. PloS one 7(9): e45517. https://doi.org/10.1371/journal.pone.0045517

Garay-Mendoza D et al (2018) The effect of intra-articular injection of autologous bone marrow stem cells on pain and knee function in 
patients with osteoarthritis. Int J Rheum Dis 21(1):140-147. https:// doi.org/10.1111/1756-185X.13139

Ghani MANMA et al. (2016) Allogeneic mesenchymal stem cells for osteoarthritis - Full Text View - ClinicalTrials.gov. Available at: https://clinicaltrials.gov/ct2/show/NCT01448434 (Accessed: 14 May 2019).

de Girolamo L et al (2010) Treatment of chondral defects of the knee with one step matrix-assisted technique enhanced by autologous concentrated bone marrow: in vitro characterisation of mesenchymal stem cells from iliac crest and subchondral bone. Injury 41(11):11721177. https://doi.org/10.1016/j.injury.2010.09.027

Gould D et al (2001) Visual Analogue Scale (VAS). J Clin Nurs 10(1990): 697-706

Gupta PK et al (2016a) Efficacy and safety of adult human bone marrowderived, cultured, pooled, allogeneic mesenchymal stromal cells (Stempeucel ${ }^{\circledR}$ ): preclinical and clinical trial in osteoarthritis of the knee joint. Arthritis Res Ther. BioMed Central 18(1):301. https:// doi.org/10.1186/s13075-016-1195-7

Gupta PK et al (2016b) Efficacy and safety of adult human bone marrowderived, cultured, pooled, allogeneic mesenchymal stromal cells (Stempeucel ${ }^{\circledR}$ ): preclinical and clinical trial in osteoarthritis of the knee joint. Arthritis Res Ther 18(1):301. https://doi.org/10.1186/ s13075-016-1195-7

Hass R et al (2011) Different populations and sources of human mesenchymal stem cells (MSC): a comparison of adult and neonatal tissuederived MSC. Cell Commun Signal 9(1):12. https://doi.org/10. 1186/1478-811X-9-12

Hudetz D et al (2017) The effect of intra-articular injection of autologous microfragmented fat tissue on proteoglycan synthesis in patients with knee osteoarthritis. Genes 8(10):270. https://doi.org/10.3390/ genes 8100270

Jo CH et al (2014) Intra-articular injection of mesenchymal stem cells for the treatment of osteoarthritis of the knee: a proof-of-concept clinical trial. Stem Cells 32(5):1254-1266. https://doi.org/10.1002/stem.1634

Jo CH et al (2017) Intra-articular injection of mesenchymal stem cells for the treatment of osteoarthritis of the knee: a 2-year follow-up study. Am J Sports Med 45(12):2774-2783. https://doi.org/10.1177/ 0363546517716641

Kellgren JH, Lawrence JS (1957) Radiological assessment of osteo-arthrosis. Ann Rheum Dis 16(4):494-502. https://doi.org/10.1136/ard. 16.4.494

Kim HJ, Im GI (2009) Chondrogenic differentiation of adipose tissuederived mesenchymal stem cells: greater doses of growth factor are necessary. J Orthop Res 27(5):612-619. https://doi.org/10.1002/jor. 20766

Koga H, Muneta T et al (2008a) Comparison of mesenchymal tissuesderived stem cells for in vivo chondrogenesis: suitable conditions for cell therapy of cartilage defects in rabbit. Cell Tissue Res 333(2): 207-215. https://doi.org/10.1007/s00441-008-0633-5

Koga H, Shimaya M, Muneta T, Nimura A, Morito T, Hayashi M, Suzuki S, Ju YJ, Mochizuki T and Sekiya I (2008b) Local adherent technique for transplanting mesenchymal stem cells as a potential treatment of cartilage defect. Arthritis Res Ther 10(4):R84. https://doi. org/10.1186/ar2460

Lamo-Espinosa JM et al (2018) Intra-articular injection of two different doses of autologous bone marrow mesenchymal stem cells versus hyaluronic acid in the treatment of knee osteoarthritis: long-term follow up of a multicenter randomized controlled clinical trial (phase I/II). J Transl Med 16(1):213. https://doi.org/10.1186/s12967-018$1591-7$.

Lee B (2018) INVOSSA, a first-in-class of cell and gene therapy for osteoarthritis treatment: the phase III trial. Osteoarthr Cartil. Elsevier 26:S43-S44. https://doi.org/10.1016/j.joca.2018.02.103

Lequesne M (1991) Indices of severity and disease activity for osteoarthritis. Semin Arthritis Rheum 20(6 SUPPL. 2):48-54. https://doi. org/10.1016/0049-0172(91)90027-W
Lequesne MG (1997) The algofunctional indices for hip and knee osteoarthritis. J Rheumatol 24(4):779-781

Lequesne MG et al (1987) Indexes of severity for osteoarthritis of the hip and knee: validation-value in comparison with other assessment tests. Scand J Rheumatol 16(S65):85-89. https://doi.org/10.3109/ 03009748709102182

Liebergall M et al (2013) Stem cell-based therapy for prevention of delayed fracture union: a randomized and prospective preliminary study. Mol Ther 21(8):1631-1638. https://doi.org/10.1038/mt.2013.109

Lim H-C et al. (2017) Follow-up study of CARTISTEM® versus microfracture for the treatment of knee articular cartilage injury or defect - Full Text View - ClinicalTrials.gov. Available at: https:// clinicaltrials.gov/ct2/show/NCT01626677 (Accessed: 14 May 2019).

Matas J, Espinoza F (2018) A study to assess safety and efficacy of umbilical cord-derived mesenchymal stromal cells in knee osteoarthritis - Full Text View - ClinicalTrials.gov. Available at: https:// clinicaltrials.gov/ct2/show/NCT02580695 (Accessed: 14 May 2019).

McHorney CA, Ware JE, Raczek AE (1993) The MOS 36-item shortform health survey (sf-36): II. Psychometric and clinical tests of validity in measuring physical and mental health constructs. Med Care 31(3):247-263. https://doi.org/10.1097/00005650199303000-00006

McHorney CA et al (1994) The MOS 36-ltem short-form health survey (SF-36): III. Tests of data quality, scaling assumptions, and reliability across diverse patient groups. Med Care 32(1):40-66. https://doi. org/10.1097/00005650-199401000-00004

MEDIPOST Co. (2019) MEDIPOST - the future of biotechnology. Available at: http://www.medi-post.com/ (Accessed: 14 May 2019).

Mitsou A et al (1990) Anterior cruciate ligament reconstruction by overthe-top repair combined with popliteus tendon plasty. J Bone Joint Surg (Br) 72(3):398-404

Musculoskeletal Transplant Foundation (2013) Musculoskeletal Transplant Foundation. Available at: https://www.mtf.org/ company/ (Accessed: 14 May 2019).

Nakamura T et al (2012) Arthroscopic, histological and MRI analyses of cartilage repair after a minimally invasive method of transplantation of allogeneic synovial mesenchymal stromal cells into cartilage defects in pigs. Cytotherapy 14(3):327-338. https://doi.org/10.3109/ 14653249.2011.638912

NIH US National Library of Medicine (2019) ClinicalTrials.gov. Available at: https://clinicaltrials.gov/ct2/home (Accessed: 14 May 2019).

Nimura A et al (2008) Increased proliferation of human synovial mesenchymal stem cells with autologous human serum: comparisons with bone marrow mesenchymal stem cells and with fetal bovine serum. Arthritis Rheum 58(2):501-510. https://doi.org/10.1002/art.23219

O'Connell B, Wragg NM, Wilson SL (2019) The use of PRP injections in the management of knee osteoarthritis. Cell Tissue Res 376(2)143152. https://doi.org/10.1007/s00441-019-02996-x

Orozco L et al (2011) Intervertebral disc repair by autologous mesenchymal bone marrow cells: a pilot study. Transplantation 92(7):822828. https://doi.org/10.1097/TP.0b013e3182298a15

Orozco L et al (2013) Treatment of knee osteoarthritis with autologous mesenchymal stem cells. Transp J 95(12):1535-1541. https://doi. org/10.1097/TP.0b013e318291a2da

Orthofix(R) (2019) Pages - Trinity Evolution ${ }^{\circledR}$. Available at: http://web. orthofix.com/Products/Pages/Trinity-Evolution.aspx (Accessed: 14 May 2019).

Park Y-B et al (2017) Cartilage regeneration in osteoarthritic patients by a composite of allogeneic umbilical cord blood-derived mesenchymal stem cells and hyaluronate hydrogel: results from a clinical trial for safety and proof-of-concept with 7 years of extended follow-up. Stem Cells Transl Med. Wiley-Blackwell 6(2):613-621. https:// doi.org/10.5966/sctm.2016-0157 
Pers Y-M et al (2016) Adipose mesenchymal stromal cell-based therapy for severe osteoarthritis of the knee: a phase I dose-escalation trial. Stem Cells Transl Med 5(7):847-856. https://doi.org/10.5966/sctm. 2015-0245

Pham PV et al. (2016) Autologous adipose stem cells and platelet rich plasma therapy for patients with knee osteoarthritis - Full Text View - ClinicalTrials.gov. Available at: https://clinicaltrials.gov/ct2/show/ NCT02142842 (Accessed: 14 May 2019).

Puissant B et al (2005) Immunomodulatory effect of human adipose tissue-derived adult stem cells: comparison with bone marrow mesenchymal stem cells. Br J Haematol 129(1):118-129. https://doi.org/ 10.1111/j.1365-2141.2005.05409.x

R-Japan Co. Ltd (2015) R-Japan obtained autologous stem cell manufacturing license from the Ministry of Health, Labour and Welfare. Available at: https://www.prnewswire.com/news-releases/ r-japan-obtained-autologous-stem-cell-manufacturing-license-fromthe-ministry-of-health-labour-and-welfare-300107427.html (Accessed: 14 May 2019).

Ruane, J. J. (2018) Investigation of mesenchymal stem cell therapy for the treatment of osteoarthritis of the knee - Full Text View ClinicalTrials.gov. Available at: https://clinicaltrials.gov/ct2/show/ NCT02958267 (Accessed: 14 May 2019)

Rush SM (2010) Trinity Evolution. Foot Ankle Spec 3(3):144-147. https://doi.org/10.1177/1938640010369643

Russo A et al (2017) Autologous and micro-fragmented adipose tissue for the treatment of diffuse degenerative knee osteoarthritis. J Exp Orthop. springer 4(1):33. https://doi.org/10.1186/s40634-0170108-2

Sakaguchi Y et al (2005) Comparison of human stem cells derived from various mesenchymal tissues: superiority of synovium as a cell source. Arthritis Rheum 52(8):2521-2529. https://doi.org/10.1002/ art. 21212

Sekiya I et al (2015) Arthroscopic transplantation of synovial stem cells improves clinical outcomes in knees with cartilage defects. Clin Orthop Relat Res 473(7):2316-2326. https://doi.org/10.1007/ s11999-015-4324-8

Shadmanfar S et al (2018) Intra-articular knee implantation of autologous bone marrow-derived mesenchymal stromal cells in rheumatoid arthritis patients with knee involvement: results of a randomized, triple-blind, placebo-controlled phase $1 / 2$ clinical trial. Cytotherapy 20(4):499-506. https://doi.org/10.1016/j.jcyt.2017.12. 009

Shapiro SA et al (2017) A prospective, single-blind, placebo-controlled trial of bone marrow aspirate concentrate for knee osteoarthritis. Am J Sports Med 45(1):82-90. https://doi.org/10.1177/ 0363546516662455

Sheinkop, M. (2014) Outcomes data of bone marrow stem cells to treat hip and knee osteoarthritis - Full Text View - ClinicalTrials.gov. Available at: https://clinicaltrials.gov/ct2/show/NCT01601951 (Accessed: 14 May 2019).

Shirasawa $S$ et al (2006) In vitro chondrogenesis of human synoviumderived mesenchymal stem cells: optimal condition and comparison with bone marrow-derived cells. J Cell Biochem 97(1):84-97. https://doi.org/10.1002/jcb.20546

Soler R et al (2016) Final results of a phase I-II trial using ex vivo expanded autologous mesenchymal stromal cells for the treatment of osteoarthritis of the knee confirming safety and suggesting cartilage regeneration. Knee 23(4):647-654. https://doi.org/10. 1016/j.knee.2015.08.013

Song Y et al (2018) Human adipose-derived mesenchymal stem cells for osteoarthritis: a pilot study with long-term follow-up and repeated injections. Regen Med 13(3):295-307. https://doi.org/10.2217/rme2017-0152

Sridharan B, Sharma B, Detamore MS (2016) A road map to commercialization of cartilage therapy in the United States of America. Tissue Eng B Rev 22(1):15-33. https://doi.org/10.1089/ten.TEB. 2015.0147

STEMPEUTICS RESEARCH PVT LTD (2019) Stempeutics Research Pvt Lts, Stempeucell, Stempeutron, Stempeucare, Cutisera, Stem Cells. Available at: http://www.stempeutics.com/stempeucel.html (Accessed: 14 May 2019).

Taghiyar, L., Gourabi, H. and Eslaminejad, M. B. (2010) Autologous transplantation of mesenchymal stem cells (MSCs) and scaffold in full-thickness articular cartilage - Full Text View ClinicalTrials.gov. Available at: https://clinicaltrials.gov/ct2/show/ NCT00850187 (Accessed: 14 May 2019).

Tegner Y, Lysholm J (1985) Rating systems in the evaluation of knee ligament injuries. Clin Orthop Relat Res (198):43-49. https://doi. org/10.1097/00003086-198509000-00007

Vega A et al (2015) Treatment of knee osteoarthritis with allogeneic bone marrow mesenchymal stem cells. Transplantation 99(8): 1681-1690. https://doi.org/10.1097/TP.0000000000000678

Vives J, Oliver-Vila I, Pla A (2015) Quality compliance in the shift from cell transplantation to cell therapy in non-pharma environments. Cytotherapy 17(8):1009-1014. https://doi.org/10.1016/j.jcyt.2015. 02.002

Wallace IJ, Worthington S, Felson DT, Jurmain RD, Wren KT, Maijanen H, Woods RJ and Lieberman DE (2017) Knee osteoarthritis has doubled in prevalence since the mid-20th century. Proc Natl Acad Sci 114(35):9332-9336. https://doi.org/10.1073/pnas.1703856114

Ware JE, Sherbourne CD (1992) The MOS 36-item short-form health survey (SF-36). I. Conceptual framework and item selection. Med Care 30(6):473-483. https://doi.org/10.1097/00005650199206000-00002

Wheeler DL et al (2014) Allogeneic mesenchymal progenitor cells for posterolateral lumbar spine fusion in sheep. Spine J 14(3):435-444. https://doi.org/10.1016/j.spinee.2013.09.048

de Windt TS et al (2017) Allogeneic mesenchymal stem cells stimulate cartilage regeneration and are safe for single-stage cartilage repair in humans upon mixture with recycled autologous chondrons. Stem Cells 35(1):256-264. https://doi.org/10.1002/stem.2475

Wolfstadt JI et al (2015) Current concepts: the role of mesenchymal stem cells in the management of knee osteoarthritis. Sports Health 7(1): 38-44. https://doi.org/10.1177/1941738114529727

Wyles CC et al (2015) Mesenchymal stem cell therapy for osteoarthritis: current perspectives. Stem Cells Cloning 8:117-124. https://doi.org/ $10.2147 /$ sccaa.s68073

Publisher's note Springer Nature remains neutral with regard to jurisdictional claims in published maps and institutional affiliations. 